\title{
Emerging roles of the extracellular calcium-sensing receptor in nutrient sensing: control of taste modulation and intestinal hormone secretion
}

\author{
Sarah C. Brennan*, Thomas S. Davies, Martin Schepelmann and Daniela Riccardi* \\ Division of Pathophysiology and Repair, Cardiff School of Biosciences, Biomedical Sciences Building, Museum Avenue, \\ Cardiff CF1O $3 A X, U K$
}

(Submitted 10 September 2012 - Final revision received 9 January 2013 - Accepted 14 January 2013)

\begin{abstract}
The extracellular Ca-sensing receptor (CaSR) is a sensor for a number of key nutrients within the body, including $\mathrm{Ca}$ ions $\left(\mathrm{Ca}^{2+}\right)$ and L-amino acids. The CaSR is expressed in a number of specialised cells within the gastrointestinal (GI) tract, and much work has been done to examine CaSR's role as a nutrient sensor in this system. This review article examines two emerging roles for the CaSR within the GI tract - as a mediator of kokumi taste modulation in taste cells and as a regulator of dietary hormone release in response to L-amino acids in the intestine.
\end{abstract}

Key words: Calcium-sensing receptor: Nutrient-sensing: Amino acids: Gastrointestinal tract: Taste modulation: Taste receptors

The Ca-sensing receptor (CaSR) is a class C G-protein-coupled receptor that was originally identified as the molecular ion sensor for free ionised extracellular $\mathrm{Ca}\left(\mathrm{Ca}_{\mathrm{O}}^{2+}\right)$ homeostasis ${ }^{(1)}$. Although CaSR's role in divalent cation metabolism has been well defined (reviewed by Brown \& MacLeod ${ }^{(2)}$ and Hofer \& Brown $^{(3)}$ ), the CaSR is expressed in a number of tissues and cell types not typically associated with $\mathrm{Ca}_{0}^{2+}$ homeostasis. Over the past few years, much work has been undertaken to elucidate the functional significance of CaSR expression in a wide number of other tissues including the brain and central nervous system $^{(4)}$, the vasculature ${ }^{(5)}$ and the gastrointestinal (GI) tract.

Although the main physiological agonist of the CaSR is $\mathrm{Ca}^{2+}$, this receptor can be activated by a diverse array of other multivalent cations including alkaline metals $\left(\mathrm{Mg}^{2+}\right.$ and $\mathrm{Sr}^{2+}$ ), polycations (spermine and spermidine) ${ }^{(6)}$, aminoglycoside antibiotics (neomycin and gentamicin) ${ }^{(7-9)}$ and cationic polypeptides (poly-L-arginine) ${ }^{(10)}$ (reviewed by Brown $\&$ MacLeod $\left.^{(2)}\right)$. Changes in ionic strength ${ }^{(11)}$ and $\mathrm{pH}^{(12)}$ also affect CaSR's activity, as low ionic strength and high $\mathrm{pH}$ enhance CaSR's sensitivity to $\mathrm{Ca}_{\mathrm{O}}^{2+}$.

Furthermore, as a class C G-protein-coupled receptor, the CaSR belongs to a family of extracellular amino acid sensors including the metabotropic glutamate receptors. The CaSR, along with the heterodimeric taste receptors (T1R1 and T1R3), and the goldfish 5.24 receptor and its mammalian orthologue GPRC6A form a distinct subgroup of broad-spectrum amino acid-sensing receptors, which have distinct yet overlapping sensitivities to different amino acids (Fig. 1).

The CaSR is allosterically activated by L-amino acids, being able to respond to aromatic, aliphatic and polar amino acids, but not to branched or positively charged amino acids ${ }^{(13)}$. In contrast, taste receptors can be activated by aliphatic, polar, branched-chain and, to a lesser extent, charged amino acids, but not by aromatic amino acids. Lastly, the goldfish 5.24/GPRC6A receptors respond to basic, aliphatic and polar amino acids $^{(14)}$. The CaSR has also been shown to respond to small peptides, including glutathione and other $\gamma$-glutamyl peptides $^{(15,16)}$.

This variety in ligands enables the CaSR to act physiologically as a multi-modal sensor for several key nutrients throughout the body, including the GI tract. Within the GI tract, the CaSR is widely expressed in a number of specialised cells including the oesophagus, stomach, small intestine and colon $^{(17-19)}$ and has roles in gastrin secretion, colonic fluid transport and intestinal epithelial cell growth, all of which have been reviewed in depth previously (see Conigrave \& Brown $^{(19)}$ and Hebert ${ }^{(20)}$ ) and are listed in Table 1. In this review article, we examine the emerging physiological functions of the CaSR in sensing dietary nutrients in two separate roles: (1) as a taste receptor for both protein and oral $\mathrm{Ca}^{2+}$ and (2) as an amino acid sensor for the release of dietary hormones within the intestine.

Abbreviations: $\mathrm{Ca}_{1}^{2+}$, intracellular $\mathrm{Ca}^{2+}$; $\mathrm{Ca}_{o}^{2+}$, ionised extracellular $\mathrm{Ca}^{2+}$; CaSR, Ca-sensing receptor; CCK, cholecystokinin; eGFP, enhanced green fluorescent protein; GI, gastrointestinal; PLC, phospholipase C.

*Corresponding authors: Dr S. C. Brennan, fax +44 29208 74116, email brennansc@cf.ac.uk; Professor D. Riccardi, fax +44 29208 74116, email riccardi@cf.ac.uk 


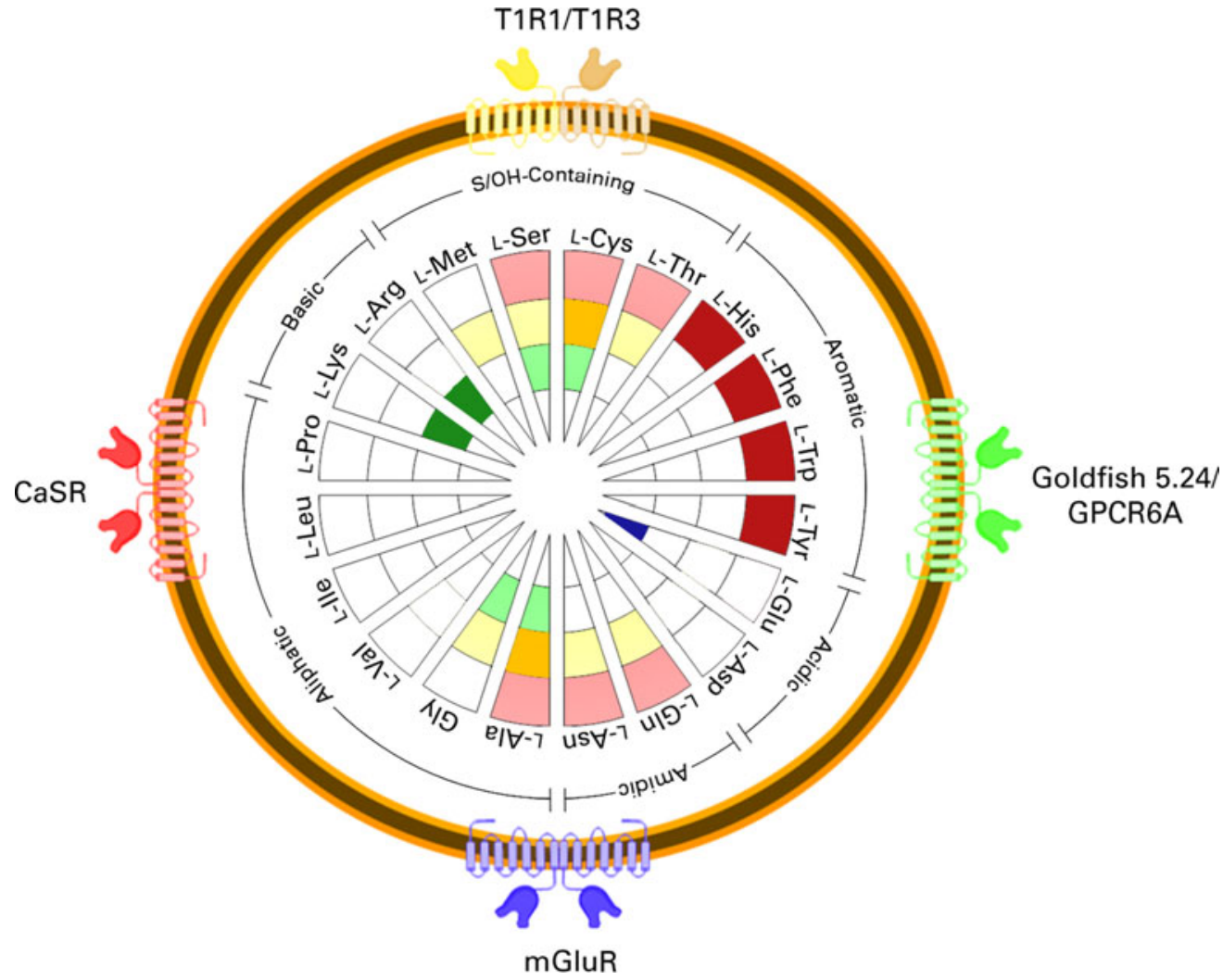

Fig. 1. Amino acid profiles of the calcium-sensing receptor (CaSR), goldfish 5.24/ GPRC6A receptors, metabotropic glutamate receptor 5 (mGluR) and type 1 taste receptor (T1R)1/T1R3 heterodimer. Effective amino acid agonists of the CaSR, goldfish 5.24/GPRC6a receptors, mGluR and T1R1/T1R3 heterodimer are shown. Data for T1R1/T1R3 efficacy were obtained from the percentage of responding cells in the HEK-293 cell population expressing the mouse T1R1/T1R3 heterodimer in the absence of $2.5 \mathrm{mM}$-inosine monophosphate and normalised to $50 \mathrm{mM}-\mathrm{L}-\mathrm{Cys}$ respons ${ }^{(53)}$. For the CaSR, amino acid efficacy was determined from the percentage of maximum reduction in half maximal effective concentration $\left(\mathrm{EC}_{50}\right)$ for extracellular $\mathrm{Ca}^{2+}$ based on the method of Conigrave et al. ${ }^{(13)}$ and normalised to the $10 \mathrm{mM}-\mathrm{L}-\mathrm{His}$ response. Normalised data were obtained from Conigrave \& Hampson ${ }^{(14)}$. We considered an effective amino acid agonist for the T1R1/T1R3 and CaSR to be one with $\geq 50 \%$ of their respective normalised responses. GPRC6A data are based on data obtained from mouse GPRC6A in the presence of $1 \mathrm{mM}-\mathrm{Ca}^{2+}$ and $1 \mathrm{~mm}-\mathrm{Mg}^{2(54,55)}$. Darker colours are used to indicate the top two to four amino acid activators for each receptor (where applicable) based on published results ${ }^{(13,14,53-55)}$. The receptor response to each amino acid is as follows: outer circle/red - CaSR; 2nd circle/yellow - T1R1/T1R3 heterodimer; 3rd circle/green - GPRC6A; and inner circle/blue - mGluR. (A colour version of this figure can be found online at http://www.journals.cambridge.org/bjn)

\section{Calcium-sensing receptor as a taste receptor}

There is now emerging evidence suggesting that the CaSR may play a role in the regulation of appetite for nutrients by modulating taste perception. The first demonstration of the possible involvement of the CaSR in taste perception was given in bullfrogs, where a positive allosteric modulator of the CaSR, the 'calcimimetic' NPS R-467, stimulated taste cells with accompanying neuronal responses ${ }^{(21)}$. Expression of the CaSR in rat and mouse taste cells, namely in the circumvallate, foliate and, to a lesser extent, the fungiform papillae, has recently been reported ${ }^{(22,23)}$.

Taste buds are generally composed of approximately 50-100 elongated taste cells, which belong to three different

Table 1. Known functions of the calcium-sensing receptor in the gastrointestinal tract

\begin{tabular}{|c|c|c|c|c|}
\hline Organ & Cell & Membrane localisation & Effect & Reference \\
\hline \multirow[t]{2}{*}{ Stomach } & G cells & Basolateral and apical & $\begin{array}{l}\text { Gastrin secretion } \\
\text { Cell growth }\end{array}$ & Buchan et al. ${ }^{(36)}$ and Feng et al. ${ }^{(56)}$ \\
\hline & Parietal cells & Basolateral & Acid secretion $\left(\mathrm{H}^{+}-\mathrm{K}^{+}\right.$ATPase $)$ & Cheng et al. ${ }^{(18)}$ and Dufner et al. ${ }^{(57)}$ \\
\hline \multirow[t]{4}{*}{ Duodenum } & $\begin{array}{l}\text { Enteric nervous } \\
\text { system cells }\end{array}$ & $\begin{array}{l}\text { Myenteric and submucosal } \\
\text { plexus, neurites and nerve fibres }\end{array}$ & $\begin{array}{l}\text { Gut motility and inhibition of } \\
\text { fluid secretion }\end{array}$ & $\begin{array}{l}\text { Chattopadhyay et al. }{ }^{(17)} \\
\text { and Cheng }\end{array}$ \\
\hline & I cells & Basolateral and apical & CCK secretion & Liou et al. ${ }^{(48)}$ \\
\hline & $\mathrm{K}$ cells & Unknown & GIP secretion & Mace et al. ${ }^{(50)}$ \\
\hline & L cells & Unknown & GLP-1 and PYY secretion & Mace et al. ${ }^{(50)}$ \\
\hline \multirow[t]{3}{*}{ Colon } & Colonocytes & Basolateral and apical & Inhibition of cell proliferation & Rey et al. ${ }^{(59,60)}$ \\
\hline & & & Stimulation of cell differentiation & Geibel \& Hebert ${ }^{(35)}$ \\
\hline & & & Inhibition of ion/fluid secretion & Cheng $^{5}$ \\
\hline
\end{tabular}

CCK, cholecystokinin; GIP, gluco-indulinotropic peptide; GLP-1, glucagon-like peptide 1; PYY, peptide tyrosine tyrosine. 
classes $^{(24,25)}$ : type I (glial-like) cells, which seem to be involved in the clearance of neurotransmitters through absorption/degradation; type II (receptor) cells, which express G-protein-coupled receptors (including the taste receptors $\mathrm{T} 1 \mathrm{R}$ and $\mathrm{T} 2 \mathrm{R})$, which bind to bitter, sweet and umami compounds, the downstream signalling components (e.g. phospholipase C $\beta 2$ (PLC $\beta 2)$ ) that transduce these taste qualities and the G-protein gustducin ${ }^{(26)}$; type III (presynaptic) cells, which form synaptic contacts with nerve terminals and are known to receive and integrate signals from type II cells.

Expression of the CaSR has been observed in type III taste cells at the mRNA and protein levels ${ }^{(22,23)}$, where the CaSR appears to be distributed throughout the plasma membrane; however, there have been conflicting reports on whether the CaSR is also expressed in type I and type II cells. Bystrova et al. ${ }^{(23)}$ showed CaSR mRNA expression at the single-cell level in a number of type I cells, but not in type II cells, using serial multistandard-assisted reverse transcriptase polymerase chain reaction (SMART-PCR); however, they were unable to demonstrate functional coupling to the PLC-dependent $\mathrm{Ca}^{2+}$ signalling pathways in type I cells.

The possibility remains that the CaSR signals in a PLCindependent manner in type I taste cells. Type I taste cells express the renal outer medullary $\mathrm{K}^{+}$channel on their apical membrane, where this channel might play a role in the recycling of the $\mathrm{K}^{+}$that accumulates in the restricted spaces between type II and type III cells ${ }^{(27)}$. This scenario would be reminiscent of the thick ascending limb of the kidney, where the activation of the basolateral CaSR has been shown to inhibit apical renal outer medullary $\mathrm{K}^{+}$through signalling pathways involving arachidonic acid and its metabolites ${ }^{(28)}$, and the type I taste cell CaSR may signal in a similar manner (Fig. 2).

Conversely, San Gabriel et al. ${ }^{(22)}$ and Maruyama et al. ${ }^{(29)}$ have demonstrated expression of the CaSR in a subset of taste cells that express either neural cell adhesion molecule (NCAM) (a marker of type III cells) or PLC 32 (a marker of type II cells) using immunofluorescence. CaSR-positive, PLC $\beta 2$-expressing type II cells did not express one of the subunits required for the sweet/umami taste receptors, T1R3 ${ }^{(29)}$; however, whether other receptors, such as the bitter T2R receptor, are co-expressed in CaSR-positive type II taste cells is currently unknown.

Interestingly, recent work ${ }^{(30)}$ has demonstrated that in CaSRexpressing HEK-293 cells this receptor may be stimulated by the bitter compound denatonium in the millimolar range. Similar to other small peptides, such as glutathione and $\gamma$-glutamyl peptides ${ }^{(15,16)}$, it seems to have a positive allosteric effect on $\mathrm{Ca}_{\mathrm{O}}^{2+}$ concentration-response curves, although whether denatonium stimulates the CaSR in taste cells is unknown ${ }^{(30)}$.

The exposure of CaSR-expressing type III taste cells to L-amino acids (L-Phe and Arg), $\gamma$-glutamyl peptides (such as glutathione and $\gamma$-glutamyl-valine-glycine) and calcimimetics (cinacalcet) has been shown to evoke intracellular $\mathrm{Ca}^{2+}\left(\mathrm{Ca}_{i}^{2+}\right)$ transients, which are ablated by the non-specific PLC inhibitor $\mathrm{U} 73122^{(23,29)}$. High concentrations $(3 \mu \mathrm{M})$ of the negative CaSR allosteric modulator, the 'calcilytic' NPS 2143, have also been shown to inhibit $\gamma$-glutamyl-valineglycine-mediated $\mathrm{Ca}_{\mathrm{i}}^{2+}$ responses, suggesting that these

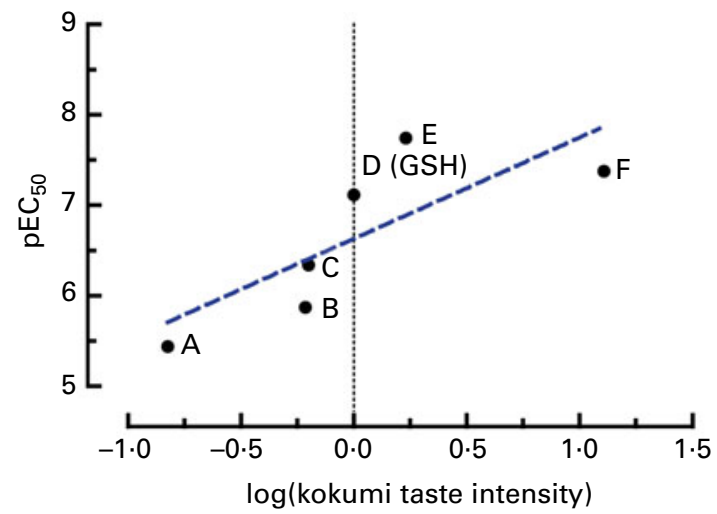

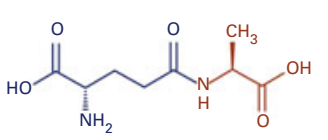

(a) y-Glu-Ala

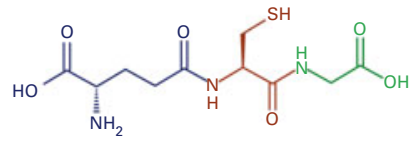

(d) y-Glu-Cys-Gly (GSH)<smiles>CC(C)C(NC(=O)CC[C@H](N)C(=O)O)C(=O)O</smiles>

(b) y-Glu-Val<smiles>N[C@@H](CCC(=O)NC(CS)C(=O)O)C(=O)O</smiles>

(c) y-Glu-cys<smiles>CCC(NC(=O)CC[C@H](N)C(=O)O)C(=O)NCC(=O)O</smiles>

(e) y-Glu-Abu-Gly<smiles>CC(C)C(NC(=O)CC[C@H](N)C(=O)O)C(=O)NCC(=O)O</smiles>

(f) y-Glu-Val-Gly
Fig. 2. Relationship between calcium-sensing receptor (CaSR) half maximal effective concentration $\left(E_{50}\right)$ values and kokumi taste intensity. A total of six $\gamma$-glutamyl peptides were tested for kokumi taste intensity by a panel of assessors. The intensity of kokumi taste was quantified in reference to the glutathione (GSH) concentration required to achieve an equivalent intensity of taste sensation. $\mathrm{EC}_{50}$ values for these substances were determined by measuring agonist-evoked increase in intracellular $\mathrm{Ca}^{2+}$ concentrations in HEK-293 cells transiently expressing human CaSR. Substances with stronger kokumi taste intensity exhibited a higher potency for CaSR activation than substances with lower kokumi taste intensity. Data were obtained from Ohsu et al. ${ }^{(31)}$ and redrawn. (A colour version of this figure can be found online at http://www.journals.cambridge.org/bjn)

responses might be mediated through the activation of the CaSR (Fig. 2) ${ }^{(29)}$.

Although the majority of this work has been completed in rodent taste cells, there is evidence that the CaSR plays a role in human taste transduction. Human sensory analysis has demonstrated that a number of CaSR activators, including glutathione and $\gamma$-glutamyl-valine-glycine, act as kokumi taste substances ${ }^{(31)}$, enhancing sweet, salty and umami tastes without producing a taste of their own. There seems to be a positive correlation between kokumi taste intensity and CaSR agonist activity, as determined by the half maximal effective concentration $\left(\mathrm{EC}_{50}\right)$ values in CaSR-expressing HEK-293 cells (Fig. 3, modified from that of Ohsu et al. ${ }^{(31)}$ ). In addition, high concentrations of the calcilytic NPS 2143 have been found to significantly suppress the kokumi taste effects of CaSR agonists ${ }^{(31)}$.

There may also be an additional role for the CaSR in the oral detection of $\mathrm{Ca}_{\mathrm{O}}^{2+}$, which has a distinctive taste quality, 


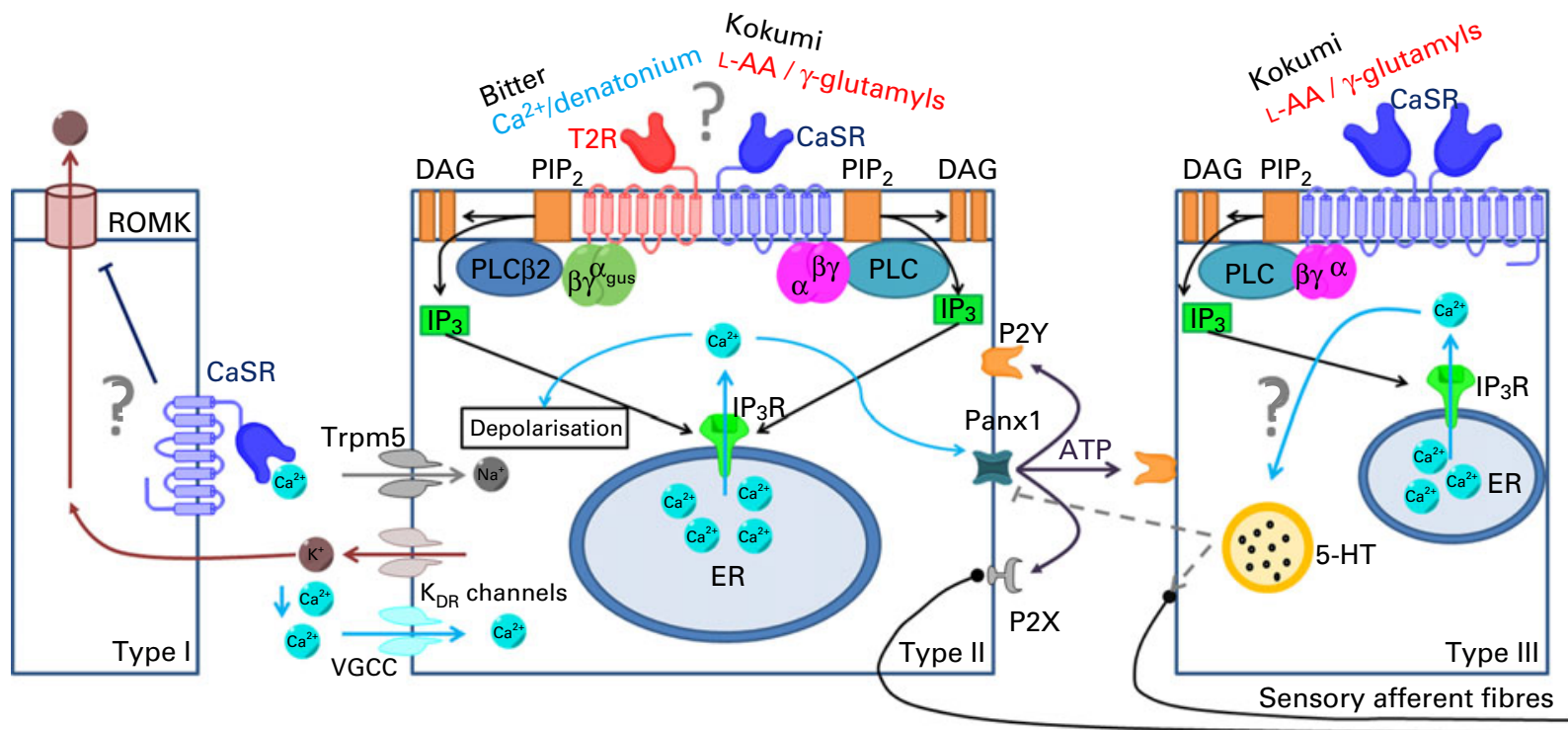

Fig. 3. Proposed roles of the calcium-sensing receptor (CaSR) within taste cells. This diagram depicts the proposed roles and signalling pathways for the CaSR in type I, II and III taste cells. In this figure, the CaSR is positioned on the membrane that is most appropriate for its postulated role. (1) In type I (glial-like) cells, activation of the basolateral CaSR may be linked to the regulation of potassium recycling by the apical renal outer medullary potassium (ROMK) channel, similar to its role in the kidney. (2) The CaSR is most probably co-expressed in type II (receptor) cells with T2R receptors on the luminal membrane, where it may play a role in the transduction of both bitter taste (oral $\mathrm{Ca}^{2+} /$ denatonium) and kokumi taste (L-amino acids (L-AA)/ $\gamma$-glutamyl). Activation of CaSR homodimers, or possible CaSR/T2R heterodimers, leads to activation of the G-protein gustducin $\left(\alpha_{\text {gus }}\right)$ and phospholipase C $\beta 2$ (PLC $\left.\beta 2\right)$. PLC $\beta 2$ catalyses the formation of inositol 1,4,5trisphosphate $\left(\mathrm{IP}_{3}\right)$ and diacylglycerol (DAG) from phosphatidylinositol 4,5-bisphophate $\left(\mathrm{PIP}_{2}\right)$, leading to the release of $\mathrm{Ca}^{2+}$ from the endoplasmic reticulum (ER) through $\mathrm{IP}_{3}$ binding to an $\mathrm{IP}_{3}$ receptor $\left(\mathrm{IP}_{3} \mathrm{R}\right)$. Increased intracellular $\mathrm{Ca}^{2+}$ concentrations lead to the depolarisation of the cell through the actions of the $\mathrm{Na}^{+}$ channel transient receptor potential cation channel, subfamily M, member 5 (Trpm5), delayed rectifying potassium channels $\left(K_{D R}\right.$ channels) and voltage-gated calcium channels (VGCC). Furthermore, the cells release ATP through pannexin 1 (Panx1), exciting the ATP receptors P2Y and P2X on sensory never fibres ${ }^{(25)}$. (3) In type III presynaptic cells, activation of the apical CaSR by $\gamma$-glutamyl peptides leads to an increase in intracellular $\mathrm{Ca}^{2+}$ concentrations by a PLC-dependent pathway. An increase in intracellular $\mathrm{Ca}^{2+}$ concentrations in type III cells is linked to the release of the serotonin 5-hydroxytryptamine (5-HT), which can inhibit type II receptor cells; however, whether this occurs in a CaSR-dependent manner is currently unknown. (A colour version of this figure can be found online at http://www.journals.cambridge.org/bjn)

with aqueous Ca-containing solutions tasting quite bitter to humans ${ }^{(32)}$. Interestingly, Ca deprivation has been shown to increase the palatability of $\mathrm{Ca}$ in rodents ${ }^{(33)}$. The exact mechanism by which animals detect/'taste' $\mathrm{Ca}$ is still yet to be fully elucidated; however, previous work ${ }^{(33)}$ has implicated the involvement of the T1R3 receptor. It has been suggested that the T1R3 receptor may heterodimerise with the CaSR to form a functional $\mathrm{Ca}^{2+}$ sensor in type II taste cells ${ }^{(33)}$; however, there is no evidence to date that the expression of T1R3 and that of the CaSR overlap ${ }^{(23,29)}$.

As the activation of the CaSR-positive taste cells has already been implicated in the modulation of kokumi taste, it is perhaps not such a great leap to imagine that the CaSR could play a similar role in the detection of oral $\mathrm{Ca}$. In support of this argument is the finding that a substantial proportion of variation in Ca taste preference among mice is due to CaSR polymorphisms $^{(34)}$.

\section{Calcium-sensing receptor in the intestine}

The CaSR is present in the stomach, where its activation stimulates the secretion of gastrin (by G cells) and of $\mathrm{H}^{+}$(by antral cells) (reviewed by Geibel \& Hebert ${ }^{(35)}$ ). In gastrin-secreting $G$ cells, the CaSR is expressed on both the apical and basolateral membranes ${ }^{(36)}$, suggesting that they have the ability to respond to changes in both the luminal contents and blood ${ }^{(19)}$, whereas in parietal cells, the CaSR is expressed only on the basolateral membrane ${ }^{(18)}$, which could allow the stimulation of gastric acid secretion by intestinally absorbed $\mathrm{L}$-amino acids ${ }^{(19)}$.

Seminal studies carried out by Geibel \& Hebert ${ }^{(35)}$ have demonstrated that the CaSR, expressed on both the apical and basolateral membranes of colonic crypts, plays a fundamental role in the colon in $\mathrm{NaCl}$ and water transport and raises the possibility of using CaSR-based therapeutics to prevent toxininduced secretory diarrhoea, one of the most debilitating conditions in underdeveloped countries. Luminal $\mathrm{Ca}^{2+}$ also promotes gut epithelial differentiation, while CaSR-mediated signalling suppresses gut cell proliferation while preserving epithelial integrity ${ }^{(37)}$. Dietary $\mathrm{Ca}^{2+}$ intake is associated with a reduced risk of colon cancer and CaSR expression is absent in colon cancer specimens while being highly abundant in normal tissue from the same patients (see Rogers et al. ${ }^{(38)}$ for a review). While a definitive and direct link between loss of CaSR expression and malignant transformation in the gut remains to be elucidated, it has been hypothesised that the CaSR might be a drug target for the treatment of colon cancer.

Recent evidence has demonstrated that the CaSR also plays an important role in the regulation of hormone secretion in intestinal enteroendocrine cells in response to L-amino acids. Aromatic amino acids have been shown to mediate the secretion of the GI hormone cholecystokinin $(\mathrm{CCK})^{(39-43)}$. The secretion of CCK from enteroendocrine cells in the 
small intestine is a major regulator for the release of bile by the gall bladder, as well as the secretion of digestive enzymes from the pancreas ${ }^{(37,42)}$. CCK also acts as a satiety hormone, reducing food intake in various species, including humans ${ }^{(44)}$.

Due to the difficulties in obtaining sufficient amounts of homogeneous I cells from intestinal tissue, initial experiments examining the cellular mechanism by which aromatic amino acids mediate CCK secretion had focused on the murine enteroendocrine cell line STC-1. Here, L-Phe was shown to stimulate CCK secretion in a $\mathrm{Ca}_{\mathrm{O}}^{2+}$-dependent manner (Fig. 4(a) and (b)) ${ }^{(45)}$. L-Phe also increased $\mathrm{Ca}_{\mathrm{i}}^{2+}$ concentrations and $\mathrm{Ca}^{2+}$ channel activity, while the $\mathrm{Ca}^{2+}$ channel blocker diltiazem inhibited CCK secretion ${ }^{(45)}$. Phe-mediated secretion is also stereoselective for the natural L-isomer (Fig. 4(a)). High concentrations of the calcilytic NPS 2143 abolished L-Phe-stimulated CCK secretion, suggesting that the CaSR may play a role in L-Phe mediated CCK secretion in STC-1 cells. Consistent with this hypothesis, CaSR mRNA expression was detected in STC-1 cells using RT-PCR ${ }^{(46)}$. Recent work $^{(47)}$ has also demonstrated that the STC-1 cells
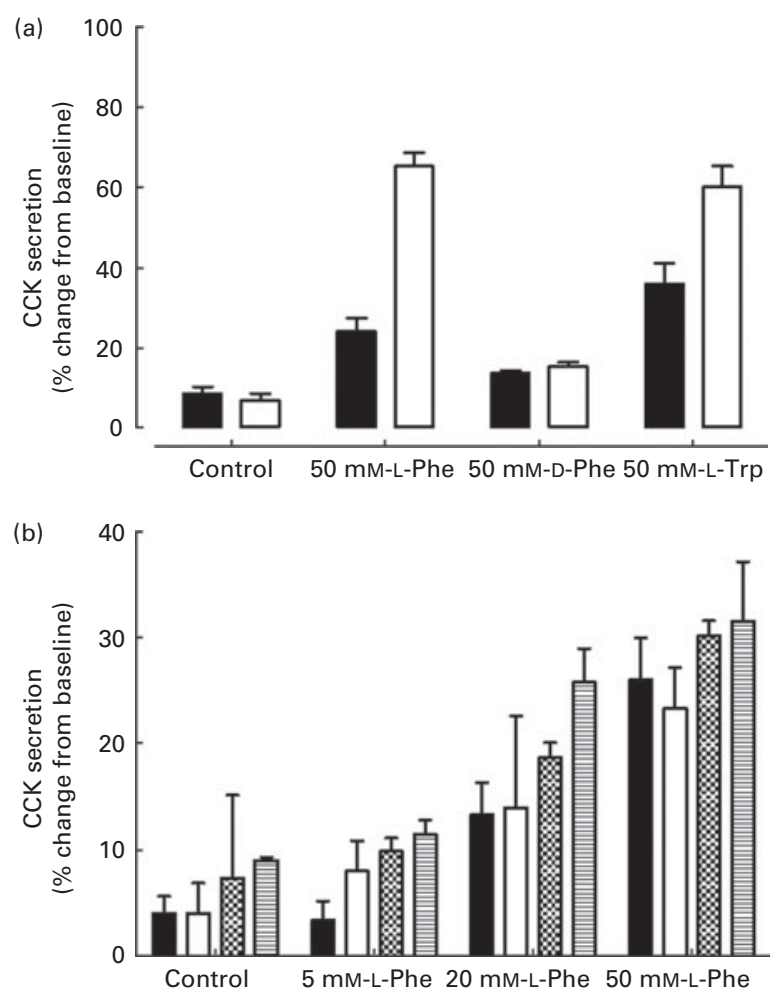

Fig. 4. L-Amino acid-induced cholecystokinin (CCK) secretion from STC-1 cells. (a) Stimulation of CCK secretion in response to L-Phe, L-Trp and D-Phe at $1.5 \mathrm{~mm}-\mathrm{Ca}_{0}^{2+}(\square)$ or $3.0 \mathrm{~mm}-\mathrm{Ca}_{0}^{2+}(\square)$ concentrations in STC-1 cells. Both the Ca-sensing receptor-active aromatic amino acids L-Phe and L-Trp stimulated increases in CCK secretion in a calcium-dependent manner. CCK secretion was stereoselective, as exposure to D-Phe had a minimal effect on CCK secretion. (b) Concentration-dependent CCK secretion in STC-1 cells. Increasing concentrations of both $\mathrm{Ca}_{\circ}^{2+}$ and L-Phe induced increases in CCK secretion in a concentration-dependent manner in STC-1 cells.

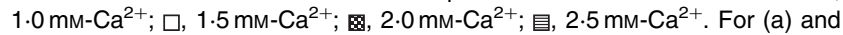
(b), STC-1 cells were exposed to various agonists at different $\mathrm{Ca}_{\circ}^{2+}$ concentrations $(1-3 \mathrm{~mm})$ for $30 \mathrm{~min}$ at $37^{\circ} \mathrm{C}$ before CCK secretion was determined using a commercial CCK enzyme immunoassay kit (Phoenix Pharmaceuticals, Inc.). Values are \% mean change from baseline, with their standard errors from three to four wells represented by vertical bars. respond to protein hydrolysates (such as egg albumin, meat, potato, casein and soyabean) with an increase in CCK secretion, which is suppressed in the presence of NPS 2143, except for meat hydrolysate-induced CCK secretion. Together, these studies strongly support a role for the CaSR as an amino acid sensor in these cells.

The involvement of the CaSR in the mediation of CCK secretion has been elucidated by two groups using bacterial artificial chromosome transgenic mice, which permitted the identification of specific cell types using enhanced green fluorescent protein (eGFP). This elegant approach has permitted the isolation of CCK-secreting cells from CCKeGFP bacterial artificial chromosome transgenic mice by fluorescence-activated cell sorting ${ }^{(48,49)}$.

The first such study, carried out by Liou et al. ${ }^{(48)}$, used fluorescence-activated cell sorting to isolate native CCKsecreting duodenal I cells from CCK-eGFP bacterial artificial chromosome mice. Using quantitative RT-PCR, these isolated CCK-eGFP cells were shown to express CaSR mRNA transcripts at a level approximately 900-fold higher than that in non-eGFP-expressing cells, and the presence of CaSR protein was confirmed with immunofluorescence. The exposure of isolated I cells to phenylalanine induced intracellular $\mathrm{Ca}^{2+}$ influx, which was $\mathrm{Ca}_{\mathrm{O}}^{2+}$ dependent and stereoselective for L-Phe. L-Phe-dependent CCK secretion in native I cells was enhanced in the presence of supraphysiological $\mathrm{Ca}_{\mathrm{o}}^{2+}$ concentrations, indicating a synergistic effect of $\mathrm{Ca}_{\mathrm{O}}^{2+}$ and this amino acid. Interestingly, supraphysiological $\mathrm{Ca}_{\mathrm{O}}^{2+}$ concentrations alone were unable to evoke an increase in CCK secretion. Based on these results, the authors concluded that the CaSR acts as an amino acid sensor in this physiological setting ${ }^{(48)}$.

Deletion of the CaSR from CCK-eGFP I cells did not affect basal CCK secretion; however, L-Phe-mediated $\mathrm{Ca}_{\mathrm{i}}^{2+}$ influx was lost. Furthermore, L-Phe and supraphysiological $\mathrm{Ca}_{\mathrm{O}}^{2+}$ concentrations surprisingly suppressed CCK secretion by approximately $20-30 \%$ in these cells, compared with basal levels, suggesting that not only is the CaSR required for L-Phe-mediated CCK secretion, but also the absence of a fully functional receptor may inhibit L-amino acid-induced CCK secretion ${ }^{(48)}$

The second study, carried out by Wang and colleagues, examined CCK-secreting intestinal mucosal cells in CCKeGFP bacterial artificial chromosome transgenic mice. Expression of the CaSR was confirmed with quantitative RT-PCR and immunofluorescence and was found to be localised in both the apical and basolateral regions of CCKeGFP cells, similar to that shown in the study carried out by Liou et $\mathrm{al}^{(48)}$. Aromatic amino acids L-Phe and L-Trp, but not the non-aromatic amino acid L-Ala, caused transient increases in $\mathrm{Ca}_{\mathrm{i}}^{2+}$ concentrations and stimulated CCK secretion. Antagonisation of the CaSR with the calcilytic Calhex 231 blocked aromatic amino acid-mediated CCK secretion, without affecting the effect of hyperpolarising concentrations of $\mathrm{KCl}$, again pointing to a role for the CaSR in the modulation of the effects of certain amino acids on CCK secretion ${ }^{(49)}$.

Recently, the CaSR has also been implicated in the regulation of $\mathrm{K}$ - and L-cell activity in response to $\mathrm{L}$-amino acids ${ }^{(50)}$. Isolated loops of the rat small intestine were used to quantify the 
secretion of three anti-diabetic gut peptides (gluco-indulinotropic peptide, glucagon-like peptide 1 and peptide tyrosine tyrosine) in response to a number of $L$-amino acids.

L-Phe, L-Trp, L-Arg, L-Asn and L-Gln induced the secretion of gluco-indulinotropic peptide, glucagon-like peptide 1 and peptide tyrosine tyrosine in the presence of physiological $\mathrm{Ca}_{\mathrm{o}}^{2+}$ concentrations (i.e. $1.25 \mathrm{~mm}$ ). Characteristic of a CaSRmediated response, L-amino acid-induced secretion responses were abolished in the absence of $\mathrm{Ca}_{\mathrm{O}}^{2+}$ for all the three peptides. High concentrations of the CaSR antagonist Calhex 231 suppressed L-amino acid secretion responses to various degrees, with the exception of L-Gln-stimulated glucagonlike peptide 1 secretion $^{(50)}$. Inhibition of the CaSR by Calhex 231 was most efficient at suppressing aromatic amino acid responses ${ }^{(50)}$, perhaps unsurprisingly as it is the most potent CaSR ligand ${ }^{(13)}$. Furthermore, the addition of a CaSR allosteric agonist, NPS R568, after the initial elevation of gluco-indulinotropic peptide, glucagon-like peptide 1 or peptide tyrosine tyrosine secretion by L-amino acids further enhanced secretion to a maximal level, while an increase in $\mathrm{Ca}_{\mathrm{o}}^{2+}$ concentrations increased the potency of L-Phe-induced L-/K-cell response.

\section{Summary and conclusion}

The role of the CaSR in nutrient sensing within the GI system continues to evolve with time. Previous studies ${ }^{(51,52)}$ have demonstrated that a protein-rich diet improves bone health and is associated with a reduced risk of fracture and an improved post-fracture recovery, underlying a link between dietary protein intake and Ca metabolism. New developments, presented in this review article, implicate the involvement of the CaSR in the modulation of appetite and control of satiety and anti-diabetic hormone secretion in response to amino acids/dietary $\mathrm{Ca}$. Overall, these findings present the CaSR as a possible new therapeutic target in the ongoing fight against obesity and osteoporosis and their related disorders.

\section{Acknowledgements}

The authors are grateful to Professor Arthur Conigrave and Professor Steve Simpson from the University of Sydney for allowing the inclusion of previously unpublished CCK secretion data obtained by S. C. B. in their laboratory. They acknowledge the Marie Curie ITN 'Multifaceted CaSR' for providing financial support (grant 264663 to D. R.). T. S. D. is a recipient of a BBSRC-CASE studentship.

The authors' contributions are as follows: S. C. B. prepared the manuscript; T. S. D. and M. S. assisted in revising the manuscript and preparing the figures; D. R. was involved in the preparation and editing of the manuscript. All the authors read and approved the final manuscript.

The authors have no conflicts of interest to declare

\section{References}

1. Brown EM, Gamba G, Riccardi D, et al. (1993) Cloning and characterization of an extracellular $\mathrm{Ca}(2+)$-sensing receptor from bovine parathyroid. Nature 366, 575-580.
2. Brown EM \& MacLeod RJ (2001) Extracellular calcium sensing and extracellular calcium signaling. Physiol Rev 81, 239-297.

3. Hofer AM \& Brown EM (2003) Extracellular calcium sensing and signalling. Nat Rev Mol Cell Biol 4, 530-538.

4. Bandyopadhyay S, Tfelt-Hansen J \& Chattopadhyay N (2010) Diverse roles of extracellular calcium-sensing receptor in the central nervous system. $J$ Neurosci Res 88, 2073-2082.

5. Weston AH, Geraghty A, Egner I, et al. (2011) The vascular extracellular calcium-sensing receptor: an update. Acta Physiol (Oxf) 203, 127-137.

6. Quinn SJ, Ye CP, Diaz R, et al. (1997) The $\mathrm{Ca}^{2+}$-sensing receptor: a target for polyamines. Am J Physiol 273, 4 Pt 1, C1315-C1323

7. Brown EM, Butters R, Katz C, et al. (1991) Neomycin mimics the effects of high extracellular calcium concentrations on parathyroid function in dispersed bovine parathyroid cells. Endocrinology 128, 3047-3054.

8. McLarnon S, Holden D, Ward D, et al. (2002) Aminoglycoside antibiotics induce $\mathrm{pH}$-sensitive activation of the calcium-sensing receptor. Biochem Biophys Res Commun 297, 71-77.

9. Ward DT, McLarnon SJ \& Riccardi D (2002) Aminoglycosides increase intracellular calcium levels and ERK activity in proximal tubular OK cells expressing the extracellular calcium-sensing receptor. J Am Soc Nephrol 13, 1481-1489.

10. Brown EM, Katz C, Butters R, et al. (1991) Polyarginine, polylysine, and protamine mimic the effects of high extracellular calcium concentrations on dispersed bovine parathyroid cells. J Bone Miner Res 6, 1217-1225.

11. Quinn SJ, Kifor O, Trivedi S, et al. (1998) Sodium and ionic strength sensing by the calcium receptor. J Biol Chem $\mathbf{2 7 3}$, 19579-19586.

12. Quinn SJ, Bai M \& Brown EM (2004) pH Sensing by the calcium-sensing receptor. J Biol Chem 279, 37241-37249.

13. Conigrave AD, Quinn SJ \& Brown EM (2000) L-Amino acid sensing by the extracellular $\mathrm{Ca}^{2+}$-sensing receptor. Proc Natl Acad Sci U S A 97, 4814-4819.

14. Conigrave AD \& Hampson DR (2006) Broad-spectrum L-amino acid sensing by class $3 \mathrm{G}$-protein-coupled receptors Trends Endocrinol Metab 17, 398-407.

15. Wang M, Yao Y, Kuang D, et al. (2006) Activation of family C G-protein-coupled receptors by the tripeptide glutathione. $J$ Biol Chem 281, 8864-8870.

16. Broadhead GK, Mun HC, Avlani VA, et al. (2011) Allosteric modulation of the calcium-sensing receptor by gammaglutamyl peptides: inhibition of PTH secretion, suppression of intracellular cAMP levels, and a common mechanism of action with L-amino acids. J Biol Chem 286, 8786-8797.

17. Chattopadhyay N, Cheng I, Rogers K, et al. (1998) Identification and localization of extracellular $\mathrm{Ca}(2+)$-sensing receptor in rat intestine. Am J Physiol 274, 1 Pt 1, G122-G130.

18. Cheng I, Qureshi I, Chattopadhyay N, et al. (1999) Expression of an extracellular calcium-sensing receptor in rat stomach. Gastroenterology 116, 118-126.

19. Conigrave AD \& Brown EM (2006) Taste receptors in the gastrointestinal tract. II. L-Amino acid sensing by calciumsensing receptors: implications for GI physiology. Am J Physiol Gastrointest Liver Physiol 291, G753-G761.

20. Hebert SC, Cheng S \& Geibel J (2004) Functions and roles of the extracellular $\mathrm{Ca}^{2+}$-sensing receptor in the gastrointestinal tract. Cell Calcium 35, 239-247.

21. Okada Y, Imendra KG, Miyazaki T, et al. (2007) A calciumreceptor agonist induces gustatory neural responses in bullfrogs. Cell Mol Neurobiol 27, 771-781.

22. San Gabriel A, Uneyama H, Maekawa T, et al. (2009) The calcium-sensing receptor in taste tissue. Biochem Biophys Res Commun 378, 414-418. 
23. Bystrova MF, Romanov RA, Rogachevskaja OA, et al. (2010) Functional expression of the extracellular- $\mathrm{Ca}^{2+}$-sensing receptor in mouse taste cells. J Cell Sci 123, Pt 6, 972-982.

24. Finger TE (2005) Cell types and lineages in taste buds. Chem Senses 30, Suppl. 1, i54-i55.

25. Chaudhari N \& Roper SD (2010) The cell biology of taste. J Cell Biol 190, 285-296.

26. Yang R, Tabata S, Crowley HH, et al. (2000) Ultrastructural localization of gustducin immunoreactivity in microvilli of type II taste cells in the rat. J Comp Neurol 425, 139-151.

27. Dvoryanchikov G, Sinclair MS, Perea-Martinez I, et al. (2009) Inward rectifier channel, ROMK, is localized to the apical tips of glial-like cells in mouse taste buds. J Comp Neurol 517, $1-14$.

28. Wang WH, Lu M \& Hebert SC (1996) Cytochrome P-450 metabolites mediate extracellular $\mathrm{Ca}(2+)$-induced inhibition of apical $\mathrm{K}^{+}$channels in the TAL. Am J Physiol 271, 1 Pt 1 , C103-C111.

29. Maruyama Y, Yasuda R, Kuroda M, et al. (2012) Kokumi substances, enhancers of basic tastes, induce responses in calcium-sensing receptor expressing taste cells. PLoS One 7, e34489.

30. Rogachevskaja OA, Churbanov GD, Bystrova MF, et al. (2011) Stimulation of the extracellular $\mathrm{Ca}^{2+}$-sensing receptor by denatonium. Biochem Biophys Res Commun 416, 433-436.

31. Ohsu T, Amino Y, Nagasaki H, et al. (2010) Involvement of the calcium-sensing receptor in human taste perception. J Biol Chem 285, 1016-1022.

32. Tordoff MG (1996) Some basic psychophysics of calcium salt solutions. Chem Senses 21, 417-424.

33. Tordoff MG, Shao H, Alarcon LK, et al. (2008) Involvement of T1R3 in calcium-magnesium taste. Physiol Genomics 34, 338-348.

34. Tordoff MG, Reed DR \& Shao H (2008) Calcium taste preferences: genetic analysis and genome screen of C57BL/ $6 \mathrm{~J} \times \mathrm{PWK} / \mathrm{PhJ}$ hybrid mice. Genes Brain Behav 7, 618-628.

35. Geibel JP \& Hebert SC (2009) The functions and roles of the extracellular $\mathrm{Ca}^{2+}$-sensing receptor along the gastrointestinal tract. Annu Rev Physiol 71, 205-217.

36. Buchan AM, Squires PE, Ring M, et al. (2001) Mechanism of action of the calcium-sensing receptor in human antral gastrin cells. Gastroenterology 120, 1128-1139.

37. Liddle RA, Goldfine ID, Rosen MS, et al. (1985) Cholecystokinin bioactivity in human plasma. Molecular forms, responses to feeding, and relationship to gallbladder contraction. J Clin Invest 75, 1144-1152.

38. Rogers AC, Hanly AM, Collins D, et al. (2012) Review Article: loss of the calcium-sensing receptor in colonic epithelium is a key event in the pathogenesis of colon cancer. Clin Colorectal Cancer 11, 24-30.

39. Furuse M, Chol YH, Yang SI, et al. (1991) Enhanced release of cholecystokinin in chickens fed diets high in phenylalanine or tyrosine. Comp Biochem Physiol A 99, 449-451.

40. Holtermuller KH, Herzog P, Huhn B, et al. (1980) Regulation of pancreatic and gallbladder function by absorption of intrajejunal phenylalanine in man. Klin Wochenschr 58, 307-312.

41. Mathur R \& Manchanda SK (1991) Ontogeny of phenylalanine (endogenous cholecystokinin) induced modulation of food intake in normal and undernourished rats. Prog Neuropsychopharmacol Biol Psychiatry 15, 405-413.

42. Yang SI, Furuse M, Sugishita N, et al. (1990) Effect of phenylalanine on pancreatic amylase secretion in chicks (Gallus domesticus). Comp Biochem Physiol A 97, 531-533.

43. Konturek SJ, Radecki T, Thor P, et al. (1973) Release of cholecystokinin by amino acids. Proc Soc Exp Biol Med 143, 305-309.
44. Ballinger AB \& Clark ML (1994) L-Phenylalanine releases cholecystokinin (CCK) and is associated with reduced food intake in humans: evidence for a physiological role of CCK in control of eating. Metabolism 43, 735-738.

45. Mangel AW, Prpic V, Wong H, et al. (1995) Phenylalaninestimulated secretion of cholecystokinin is calcium dependent. Am J Physiol 268, 1 Pt 1, G90-G94.

46. Hira T, Nakajima S, Eto Y, et al. (2008) Calcium-sensing receptor mediates phenylalanine-induced cholecystokinin secretion in enteroendocrine STC-1 cells. FEBS $J \mathbf{2 7 5}$, 4620-4626.

47. Nakajima S, Hira T \& Hara H (2012) Calcium-sensing receptor mediates dietary peptide-induced CCK secretion in enteroendocrine STC-1 cells. Mol Nutr Food Res 56, 753-760.

48. Liou AP, Sei Y, Zhao X, et al. (2011) The extracellular calcium-sensing receptor is required for cholecystokinin secretion in response to L-phenylalanine in acutely isolated intestinal I cells. Am J Physiol Gastrointest Liver Physiol 300, G538-G546.

49. Wang Y, Chandra R, Samsa LA, et al. (2011) Amino acids stimulate cholecystokinin release through the $\mathrm{Ca}^{2+}$-sensing receptor. Am J Physiol Gastrointest Liver Physiol 300, G528-G537.

50. Mace OJ, Schindler M \& Patel S (2012) The regulation of K- and L-cell activity by GLUT2 and the calcium-sensing receptor CasR in rat small intestine. J Physiol 590, Pt 12, 2917-2936.

51. Kerstetter JE, O'Brien KO \& Insogna KL (1998) Dietary protein affects intestinal calcium absorption. Am J Clin Nutr 68, 859-865.

52. Kerstetter JE, Caseria DM, Mitnick ME, et al. (1997) Increased circulating concentrations of parathyroid hormone in healthy, young women consuming a protein-restricted diet. Am J Clin Nutr 66, 1188-1196.

53. Nelson G, Chandrashekar J, Hoon MA, et al. (2002) An amino-acid taste receptor. Nature 416, 199-202.

54. Christiansen B, Hansen KB, Wellendorph P, et al. (2007) Pharmacological characterization of mouse GPRC6A, an L-alpha-amino-acid receptor modulated by divalent cations. Br J Pharmacol 150, 798-807.

55. Wellendorph P, Johansen LD \& Brauner-Osborne H (2009) Molecular pharmacology of promiscuous seven transmembrane receptors sensing organic nutrients. Mol Pharmacol 76, 453-465.

56. Feng J, Petersen CD, Coy DH, et al. (2010) Calcium-sensing receptor is a physiologic multimodal chemosensor regulating gastric G-cell growth and gastrin secretion. Proc Natl Acad Sci U S A 107, 17791-17796.

57. Dufner MM, Kirchhoff P, Remy C, et al. (2005) The calciumsensing receptor acts as a modulator of gastric acid secretion in freshly isolated human gastric glands. Am J Physiol Gastrointest Liver Physiol 289, G1084-G1090.

58. Cheng SX (2012) Calcium-sensing receptor inhibits secretagogue-induced electrolyte secretion by intestine via the enteric nervous system. Am J Physiol Gastrointest Liver Physiol 303, G60-G70.

59. Rey O, Young SH, Jacamo R, et al. (2010) Extracellular calcium sensing receptor stimulation in human colonic epithelial cells induces intracellular calcium oscillations and proliferation inhibition. J Cell Physiol 225, 73-83.

60. Rey O, Chang W, Bikle D, et al. (2012) Negative crosstalk between calcium-sensing receptor and beta-catenin signaling systems in colonic epithelium. J Biol Chem 287, $1158-1167$ 